\title{
Performance of the NEXT Engineering Model Power Processing Unit
}

Luis R. Pinero

Glenn Research Center, Cleveland, Ohio

Mark Hopson, Philip C. Todd, and Brian Wong

L-3 Communications Electron Technologies, Incorporated, Torrance, California 


\section{NASA STI Program . . . in Profile}

Since its founding, NASA has been dedicated to the advancement of aeronautics and space science. The NASA Scientific and Technical Information (STI) program plays a key part in helping NASA maintain this important role.

The NASA STI Program operates under the auspices of the Agency Chief Information Officer. It collects, organizes, provides for archiving, and disseminates NASA's STI. The NASA STI program provides access to the NASA Aeronautics and Space Database and its public interface, the NASA Technical Reports Server, thus providing one of the largest collections of aeronautical and space science STI in the world. Results are published in both non-NASA channels and by NASA in the NASA STI Report Series, which includes the following report types:

- TECHNICAL PUBLICATION. Reports of completed research or a major significant phase of research that present the results of NASA programs and include extensive data or theoretical analysis. Includes compilations of significant scientific and technical data and information deemed to be of continuing reference value. NASA counterpart of peer-reviewed formal professional papers but has less stringent limitations on manuscript length and extent of graphic presentations.

- TECHNICAL MEMORANDUM. Scientific and technical findings that are preliminary or of specialized interest, e.g., quick release reports, working papers, and bibliographies that contain minimal annotation. Does not contain extensive analysis.

- CONTRACTOR REPORT. Scientific and technical findings by NASA-sponsored contractors and grantees.

- CONFERENCE PUBLICATION. Collected papers from scientific and technical conferences, symposia, seminars, or other meetings sponsored or cosponsored by NASA.

- SPECIAL PUBLICATION. Scientific, technical, or historical information from NASA programs, projects, and missions, often concerned with subjects having substantial public interest.

- TECHNICAL TRANSLATION. Englishlanguage translations of foreign scientific and technical material pertinent to NASA's mission.

Specialized services also include creating custom thesauri, building customized databases, organizing and publishing research results.

For more information about the NASA STI program, see the following:

- Access the NASA STI program home page at http://www.sti.nasa.gov

- E-mail your question via the Internet to help@ sti.nasa.gov

- Fax your question to the NASA STI Help Desk at 301-621-0134

- Telephone the NASA STI Help Desk at 301-621-0390

- Write to: NASA Center for AeroSpace Information (CASI) 7115 Standard Drive Hanover, MD 21076-1320 
NASA/TM-2007-215037

AIAA-2007-5214

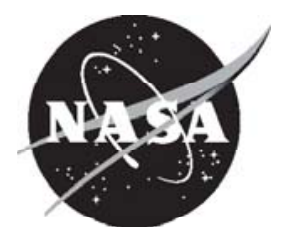

\section{Performance of the NEXT Engineering Model Power Processing Unit}

Luis R. Pinero

Glenn Research Center, Cleveland, Ohio

Mark Hopson, Philip C. Todd, and Brian Wong

L-3 Communications Electron Technologies, Incorporated, Torrance, California

Prepared for the 43rd Joint Propulsion Conference

sponsored by the American Institute of Aeronautics and Astronautics

Cincinnati, Ohio, July 8-11, 2007

National Aeronautics and

Space Administration

Glenn Research Center

Cleveland, Ohio 44135 
Level of Review: This material has been technically reviewed by technical management.

Available from

NASA Center for Aerospace Information 7115 Standard Drive

Hanover, MD 21076-1320
National Technical Information Service 5285 Port Royal Road Springfield, VA 22161

Available electronically at http://gltrs.grc.nasa.gov 


\title{
Performance of the NEXT Engineering Model Power Processing Unit
}

\author{
Luis R. Pinero \\ National Aeronautics and Space Administration \\ Glenn Research Center \\ Cleveland, Ohio 44135 \\ Mark Hopson, Philip C. Todd, and Brian Wong \\ L-3 Communications Electron Technologies, Incorporated \\ Torrance, California 90505
}

\begin{abstract}
The NASA's Evolutionary Xenon Thruster (NEXT) project is developing an advanced ion propulsion system for future NASA missions for solar system exploration. An engineering model (EM) power processing unit (PPU) for the NEXT project was designed and fabricated by L-3 Communications under contract with NASA Glenn Research Center (GRC). This modular PPU is capable of processing up from 0.5 to $7.0 \mathrm{~kW}$ of output power for the NEXT ion thruster. Its design includes many significant improvements for better performance over the state-of-the-art PPU. The most significant difference is the beam supply which is comprised of six modules and capable of very efficient operation through a wide voltage range because of innovative features like dual controls, module addressing, and a high current mode. The low voltage power supplies are based on elements of the previously validated NASA Solar Electric Propulsion Technology Application Readiness (NSTAR) PPU. The highly modular construction of the PPU resulted in improved manufacturability, simpler scalability, and lower cost. This paper describes the design of the EM PPU and the results of the bench-top performance tests.
\end{abstract}

\section{Introduction}

NASA Glenn Research Center (GRC) and its team, including Aerojet, L-3 Communications Electron Technologies, Inc., (L-3), Swales Aerospace, and the Jet Propulsion Laboratory (JPL), is developing a next generation ion propulsion system for a wide range of NASA missions to explore a variety of destinations in the solar system under the NASA's Evolutionary Xenon Thruster (NEXT) project (ref. 1). This system represents a significant improvement over the state-of-the-art (SOA) NASA's Solar Electric Propulsion Technology Application Readiness (NSTAR) ion propulsion system because each element delivers higher performance and has lower specific mass.

The NEXT system elements consist of a $36 \mathrm{~cm}$ beam diameter ion thruster, a modular $7.0 \mathrm{~kW}$ power processing unit (PPU), a highly flexible propellant management system (PMS), a lightweight gimbal, and digital control interface unit (DCIU) simulator as shown in the diagram in figure 1 . The thruster has a $36 \mathrm{~cm}$ beam diameter with 2-grid ion optics and is capable of extracting $3.52 \mathrm{~A}$ of beam current at $6.9 \mathrm{~kW}$. This is 3 times the power of the NSTAR thruster, but can still be throttled down to $0.5 \mathrm{~kW}$ (refs. 2 to 3). The PPU consists primarily of six power supplies that process power for a variety of thruster inputs and a "slice" circuit that transmits controls, status, and telemetry through a digital interface (refs. 4 to 5). The PMS consists of a high pressure assembly (HPA) and a low pressure assembly (LPA), which use a thermal-throttle flow control device and a proportional flow control valve to provide independent xenon flow control to the main discharge chamber, and the discharge and neutralizer cathodes (ref. 6). Both the PPU and PMS are controlled by the DCIU simulator computer, which will be used as a tool to develop and validate control algorithms and support system integration tests (ref. 7). The final element of the system is the lightweight thruster gimbal that can position the thruster over two axes (ref. 8). 


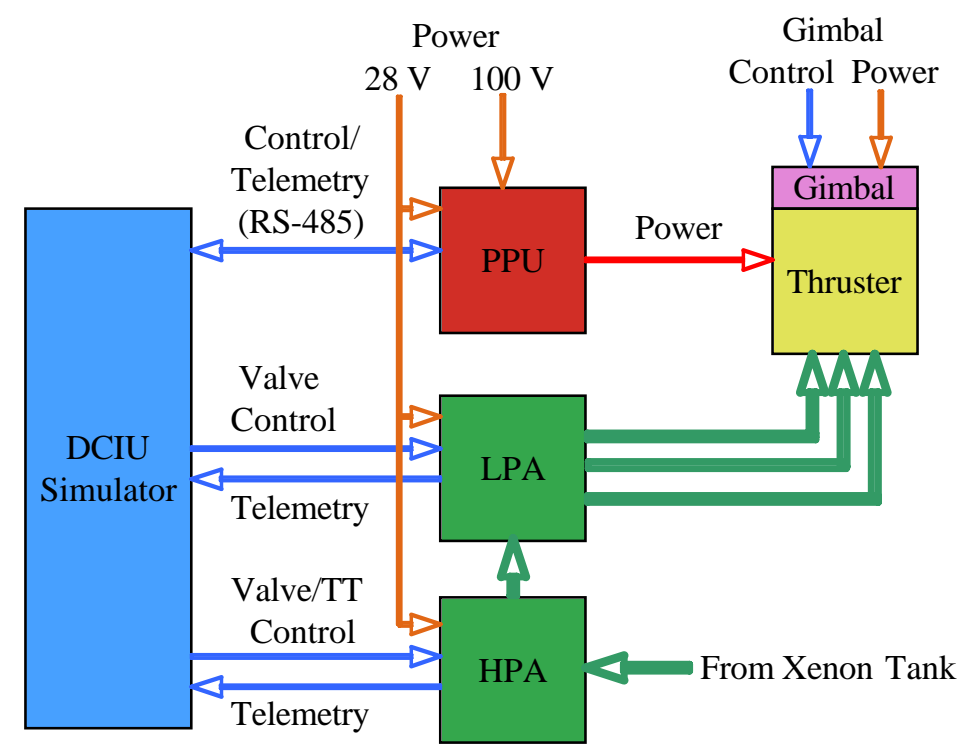

Figure 1.-Diagram of NEXT single-string elements.

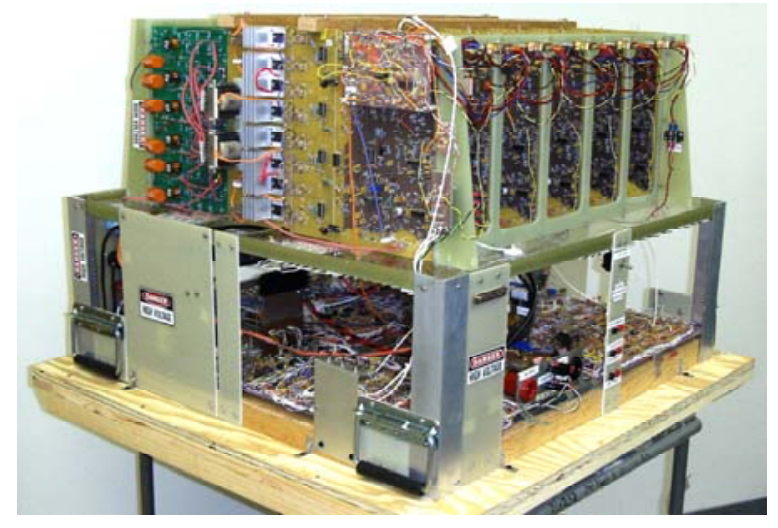

Figure 2.-NEXT breadboard PPU.

L-3 was responsible for the development of a breadboard PPU during the Phase 1 effort (ref. 5). This unit, shown in figure 2, was successfully demonstrated during a single-string integration test at GRC in the summer of 2003, which included an engineering model (EM) thruster developed by GRC and a breadboard PMS developed by Aerojet (ref. 9).

The development of an EM PPU with flight-like form, fit, and function is occurring during Phase 2. After a bench-top performance test to verify functionality, the unit will be shipped to GRC for an integration test with an EM thruster. The EM PPU will then be subjected to qualification level environmental tests including vibration, electromagnetic interference/electromagnetic compatibility (EMI/EMC), and thermal/vacuum tests at L-3. It will then be integrated with the rest of the EM system and PM thruster, under DCIU simulator control, in a single-string integration test later in 2007.

\section{PPU Specifications}

The PPU was designed to operate from two separate inputs. The high power bus (HPB) can operate at a range of 80 to $160 \mathrm{~V}_{\mathrm{DC}}$ and provides power for all PPU outputs. The low power bus (LPB) operates from a range of 22 to $34 \mathrm{~V}_{\mathrm{DC}}$ and is used exclusively for the housekeeping supply.

Six power supplies generate the power for operating the thruster. A block diagram of the PPU and its electrical interface to the thruster is shown in figure 3. Four power supplies (beam, accelerator, discharge, 


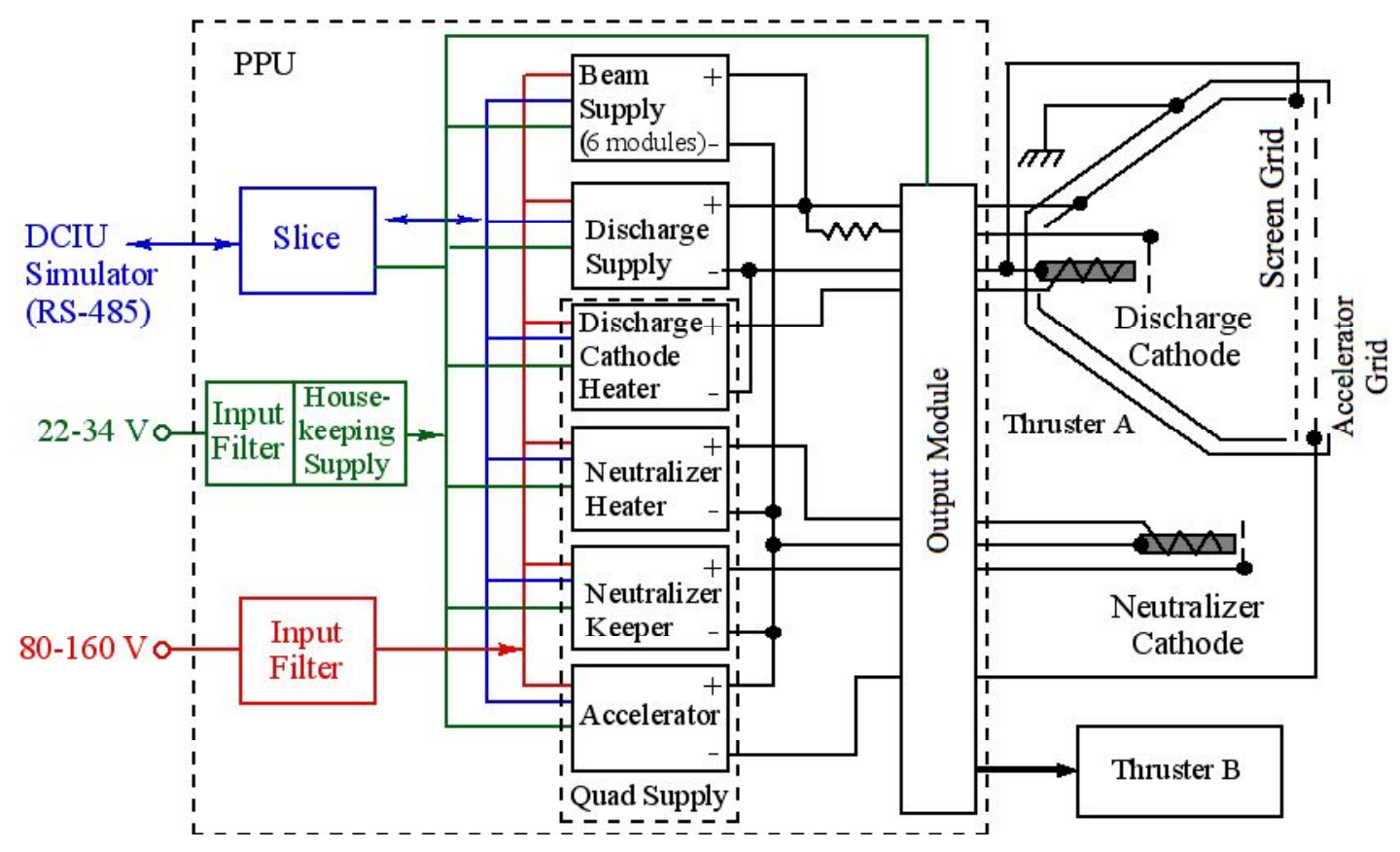

Figure 3.-PPU block diagram and electrical interfaces.

\begin{tabular}{|c|c|c|c|c|c|c|}
\hline \multicolumn{2}{|c|}{ TABLE 1.-PPU OUTPUT REQUIREMENTS } \\
\hline Beam & Accelerator & Discharge & $\begin{array}{c}\text { Neutralizer } \\
\text { Keeper }\end{array}$ & $\begin{array}{c}\text { Discharge } \\
\text { Cathode } \\
\text { Heater }\end{array}$ & $\begin{array}{c}\text { Neutralizer } \\
\text { Heater }\end{array}$ \\
\hline $\begin{array}{c}\text { Output } \\
\text { Voltage, V }\end{array}$ & 275 to 1800 & $-(115$ to 525$)$ & 15 to 35 & 8 to 32 & 3 to 24 & 3 to 12 \\
\hline $\begin{array}{c}\text { Output } \\
\text { Current, A }\end{array}$ & 1.00 to 3.53 & $\begin{array}{c}-(0 \text { to } 40) \mathrm{mA} \\
0.4 \text { surge for } \\
100 \mathrm{~ms}\end{array}$ & 4 to 24 & 1 to 3 & 3.5 to 8.5 & 3.5 to 8.5 \\
\hline $\begin{array}{c}\text { Regulation } \\
\text { Mode }\end{array}$ & Voltage & Voltage & Current & Current & Current & Current \\
\hline $\begin{array}{c}\text { Line/Load } \\
\text { Regulation }\end{array}$ & $22.5 \%$ & $22.5 \%$ & $22.5 \%$ & $22.5 \%$ & $22.5 \%$ & $22.5 \%$ \\
\hline $\begin{array}{c}\text { Output } \\
\text { Ripple }\end{array}$ & $25 \%$ & $25 \%$ & $25 \%$ & $25 \%$ & $25 \%$ & $25 \%$ \\
\hline $\begin{array}{c}\text { Igniter } \\
\text { Pulse }\end{array}$ & & & $\begin{array}{c}250 \pm 100 \mathrm{~V} \\
310 \mu \mathrm{s}\end{array}$ & $\begin{array}{c}350 \pm 100 \mathrm{~V} \\
310 \mathrm{~Hz}\end{array}$ & $\begin{array}{c}310 \mathrm{~Hz} \\
3150 \mathrm{~V} / \mu \mathrm{s}\end{array}$ & \\
\hline
\end{tabular}

and neutralizer keeper) are needed for steady state operating while two additional heater supplies (neutralizer and discharge cathode heaters) are only used during thruster startup. The most important of these power supplies is the beam supply as it processes up to 93 percent of the thruster power at voltages as high as $1800 \mathrm{~V}_{\mathrm{DC}}$. In combination with the accelerator supply, it is used to bias the thruster grids and produce thrust by accelerating the ions generated by the discharge supply. Finally, the neutralizer keeper supply provides a path for electrons to neutralize the ion beam. Table 1 summarizes the output requirements for the PPU.

The PPU is also required to exchange digital telemetry and power supply output control functions with the DCIU simulator. It also contains under-voltage and over-voltage lockout that turn-off the PPU in the case of anomalous input voltages on either power bus. In addition, it contains neutralizer and discharge current interlocks that inhibit operation of the high voltage (beam and accelerator) power supplies if cathode currents are not present. Finally, it includes recycle controls that sequence the high voltage supplies in case an over-current condition is detected in the beam supply. 


\section{PPU Design}

\section{A. Improvements Over SOA}

The NSTAR system successfully demonstrated viability of ion propulsion as primary propulsion in the Deep Space 1 (DS-1) mission (ref. 10). Subsequently, it was selected as primary propulsion for the Dawn mission (ref. 11). However, in the process of fabricating the Dawn PPUs, a number of design issues were discovered (ref. 12). The NEXT project took the initiative of addressing many of these issues since elements of the NEXT PPU come from the NSTAR design. These improvements discussed below, enhanced performance and will simplify integration of the NEXT PPU with a spacecraft in the future.

The PPU was designed with a modular approach so it can be easily adapted to a variety of mission requirements with minimum performance impact and nonrecurring cost. The design has been under configuration management at L-3 and up-to-date detailed documentation has been generated, including electrical and mechanical schematics, assembly drawings, work instructions, part lists, and test documentation. The number of subassemblies within each module was minimized by installing power semiconductors with other circuits like gate drives and control functions on the same printed wiring boards (PWB). Arrays of vias conduct the heat away from the semiconductors to aluminum heat sinks on the opposite side of the PWB. These heat sinks provide a heat path to the PPU baseplate. Connectors were used for low voltage control and telemetry signals between modules. All these changes result in improved manufacturability and reduced recurring cost.

Some improvements were made in terms of parts selection for the NEXT EM PPU. No special parts and only current surface mount packages were used. Also, power semiconductors and magnetics types were minimized. The metal oxide semiconductor field effect transistors (MOSFET) used for all the power converters are available as single event effect (SEE) radiation-hardened parts.

Several improvements impacted circuit design of the power converters and other circuits. The NEXT PPU design includes an innovative beam supply that provides improved performance through wide input and output voltage ranges and better scaling capacity. The modular beam supply uses an innovative topology with dual controls, independent module addressing, and a high-current mode that delivers higher efficiency through a larger operational range. The switching frequency of all power converters was increased to $50 \mathrm{kHz}$ to reduce size of power transformers and input and output filters. In addition, the returns of the input busses were electrically isolated to conform to JPL spacecraft requirements. Balanced EMI filters were used to reduce conducted emissions on the power returns. Also, a volt-second clamp circuit was added to the power converters to protect them from transformer saturation. Finally, the slice design was updated and, because of added capability and limitations in the speed of the DCIU simulator interface, the recycle control function was moved to the slice allowing a faster response time.

The EM PPU was designed to passively reject most waste heat by conduction to its baseplate. Some conduction to the cover is allowed. The EM PPU was designed to operate over a baseplate temperature range of -20 to $65^{\circ} \mathrm{C}$ that will be used for qualification levels. This is an improvement over the NSTAR PPU that has an upper temperature limit of $50{ }^{\circ} \mathrm{C}$ (refs. 12 and 13). Two photographs of the EM PPU are shown in figure 4 . Its dimensions are approximately 40.9 by 51.1 by $14.0 \mathrm{~cm}$ with a volume of $29,200 \mathrm{~cm}^{3}$. Its mass is $33.8 \mathrm{~kg}$ for a specific mass of $4.9 \mathrm{~kg} / \mathrm{kW}$, which is a 18 percent improvement over the NSTAR PPU. The NEXT EM PPU contains less than 4,900 parts for a $6.9 \mathrm{~kW}$ of output power for an specific parts count of 695 parts/kW. If the design is scaled to an output power level of approximately $2.3 \mathrm{~kW}$, by removing four beam modules, the parts count decreases to approximately 3,000 parts. The NSTAR PPU contained approximately 2,500 at $2.3 \mathrm{~kW}$ of output power for $1,086 \mathrm{parts} / \mathrm{kW}$. Most of the 500 additional parts in the NEXT design are related to the beam supply design and its variety of features to improve performance and flexibility. 


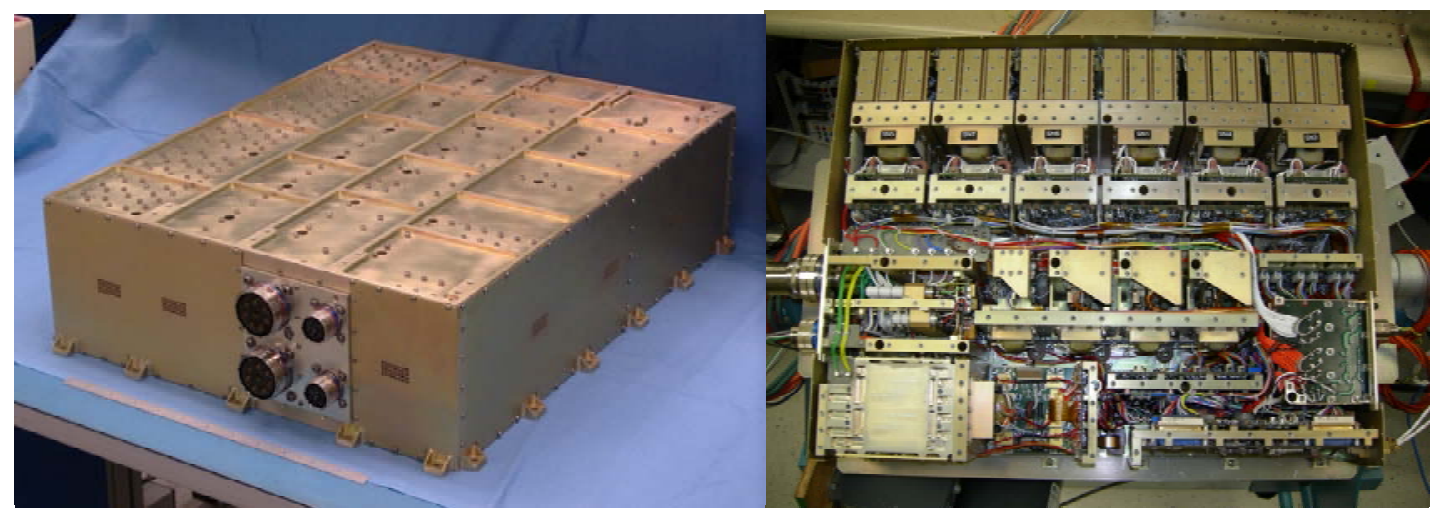

Figure 4.-NEXT engineering model PPU.

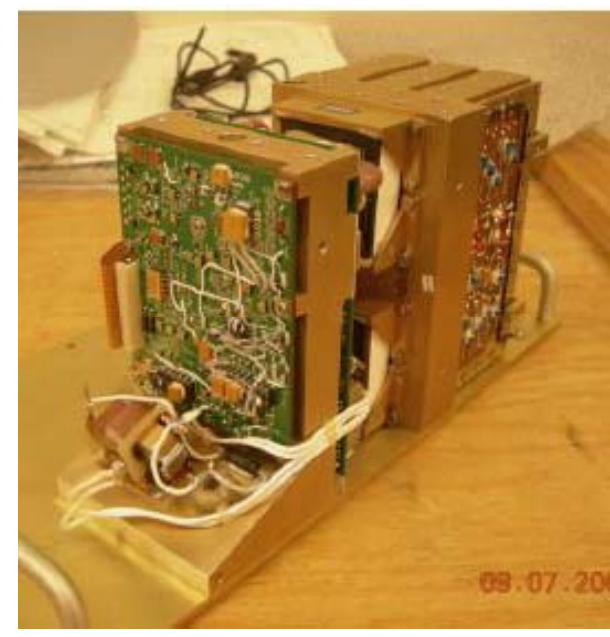

Figure 5.-Beam module.

\section{B. Beam Supply}

The beam supply consists of six power modules and a master control module. The power modules use an innovative phase-shift/pulse-width modulated dual-bridge topology that is capable of efficient operation throughout a very wide range of input and output voltages (ref. 14). The modules operate in parallel while the master module controls their operation. A module addressing circuit, controlled by the DCIU, selects the number of operational beam modules. At lower power conditions, modules can be turned off to increase efficiency of the beam supply because the housekeeping power consumption is reduced and also the remaining modules can operate closer to optimum load conditions. Also, a currentshare circuit balances the current out of each operational beam module. The synchronization of the operational modules is distributed by staggering the clock signals. This inherently reduces ripple on the input and output of the beam supply and helps reduce the size of the input filter. Another feature of the beam supply topology is the capability of operating in a high-current mode where it can output twice the rated current. This mode is operational when the converters operate in pulse-width mode at beam outputs voltages below $1000 \mathrm{~V}_{\mathrm{DC}}$.

Each beam module consists of two main assemblies. A photograph of a beam module is shown in figure 5. The power/regulator assembly contains the primary MOSFETs, input filter, and control circuits. The high voltage assembly contains two power transformers and six output rectifier stages to generate up to $1800 \mathrm{~V}_{\mathrm{DC}}$. Each module can output up to $0.67 \mathrm{~A}_{\mathrm{DC}}$ when operating in phase-shift mode and $1.34 \mathrm{~A}_{\mathrm{DC}}$ in high-current mode. 


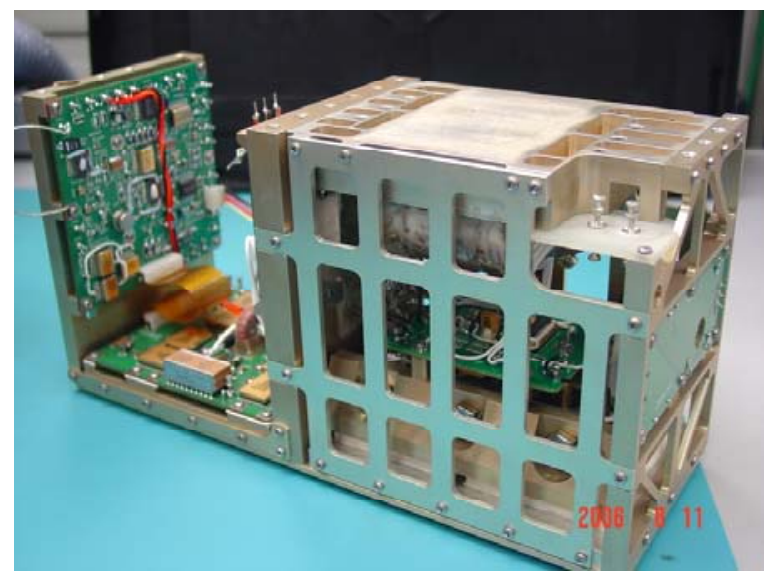

Figure 6.-Discharge supply.

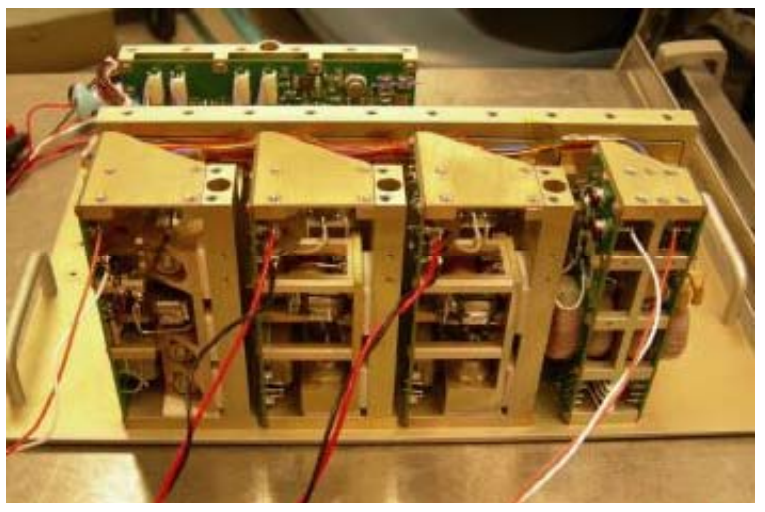

Figure 7.-Quad supply.

\section{Discharge Supply}

The NEXT discharge supply is required to process 50 percent more power than the NSTAR discharge supply. It uses the same hard-switched, full-bridge topology with current-mode PWM control to regulate the output current from 4 to $24 \mathrm{~A}_{\mathrm{DC}}$ in a single module. It also includes the pulsed igniter circuit developed for NSTAR that uses the output of the supply to power a flyback circuit using autotransformer action integrated with the output inductor (ref. 15).

The discharge supply consists of three assemblies. A photograph is shown in figure 6. The power assembly contains the primary MOSFETs, drivers, and input filter. It is mounted directly on the baseplate to reject heat effectively. Next to it is the control assembly that contains the PWM control circuit. The high voltage assembly contains the power transformer, output inductor, igniter, and output current sense PWBs.

\section{Quad Supply}

The remaining power supplies required to operate the thruster provide very low power (accelerator and neutralizer keeper) or are only used to start the thruster (neutralizer heater and discharge heater). The NEXT breadboard PPU used a similar topology to the one developed for NSTAR. These power supplies were combined in one power converter based on a full-bridge topology where the top MOSFETs were shared by all the power supplies (ref. 15). However, for the EM PPU, it was decided to change the transistor arrangement so the power supplies shared one leg of the bridge. This eliminated the need of sixteen current steering diodes on the power stage of the converter and improved module packaging and reliability. This was thought to be a simple variation on the design. However, after a failure of the keeper supply during PPU testing and a thorough investigation, it was discovered that mismatches between MOSFETs, gate drive, and control circuits could trigger an unusual failure mode in the power transistors at high input voltages. Additional adjustments were required to preclude this failure mode, and the PPU has been limited to input voltages between 80 to $120 \mathrm{~V}$ to reduce risk. It was decided to revert to the breadboard design in the following iteration of the PPU design.

The quad supply consists of six main assemblies. A photograph of a quad module is shown in figure 7. The control assembly contains the control circuits for the four power supplies. The power assembly contains the primary MOSFETs, gate driver, transformers, and input filter. Four individual output assemblies, one for each output, contain the output diodes and filters. The neutralizer keeper output subassembly also includes a pulsed igniter circuit similar to the one used in the discharge module. 


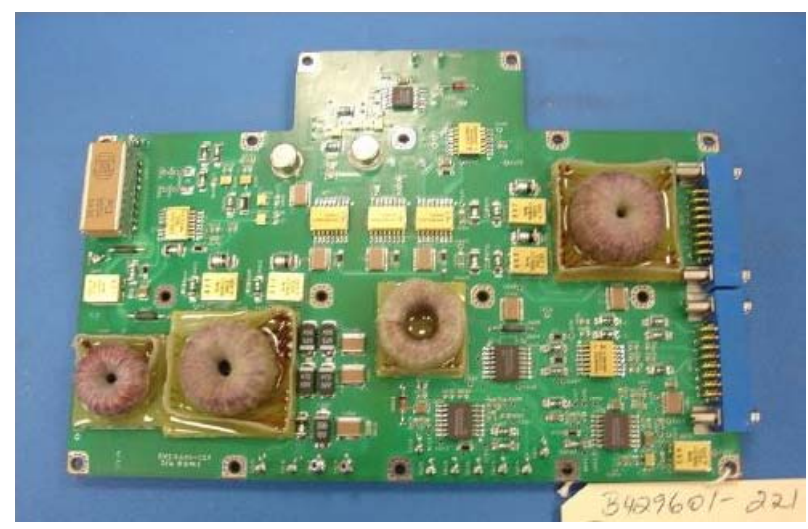

Figure 8.-Housekeeping PWB.

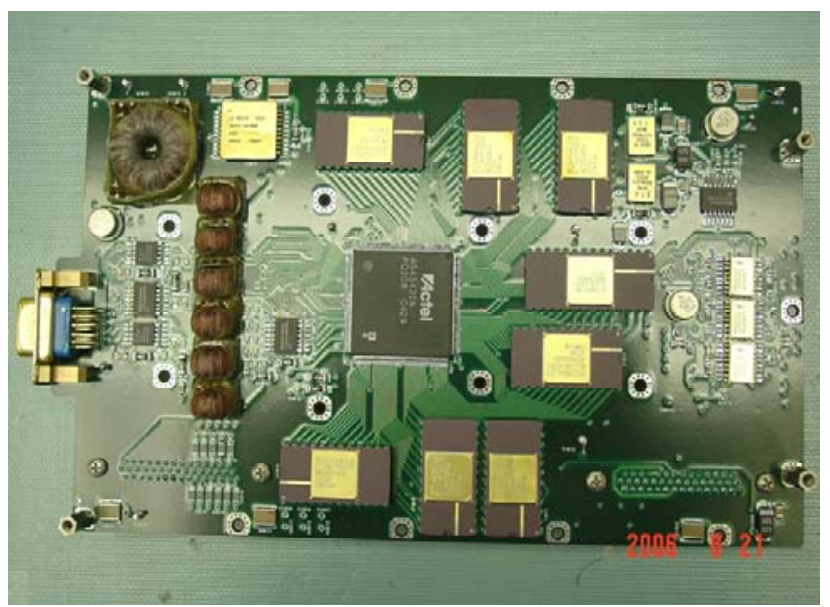

Figure 9.-Slice P WB.

\section{E. Housekeeping Supply}

The housekeeping supply provides multiple functions to the PPU. It generates power for the internal control and telemetry circuits as well as clock signals for control functions. Also, it contains the squarewave oscillators for transductors used to measure several DC currents. The housekeeping supply operates at an input of 22 to $34 \mathrm{~V}_{\mathrm{DC}}$ for the NEXT application but is capable of operation at inputs as high as $60 \mathrm{~V}_{\mathrm{DC}}$. The housekeeping supply is built in a single PWB assembly, shown in figure 8.

\section{F. Slice}

The slice allows the PPU to communicate with a DCIU simulator computer through an RS-485 interface. It contains analog-to-digital converters for telemetry, digital-to-analog converters for control setpoints, and current sources for six thermistors located at various point in the PPU. The slice monitors a recycle fault flag from the beam supply and maintains a recycle counter. All slice functions are controlled by a central field programmable gate array (FPGA). The slice is built in a single PWB assembly and is shown in figure 9.

\section{G. Other Modules}

The PPU has an input filter assembly that contains the EMI filters for the HPB and LPB. The LPB filter consists of a balanced, 4-pole, low-pass, L-C filter. The HPB filter consists of a balanced, 2-pole, single-stage, low-pass, L-C filter. An unbalanced, 2-pole stage is located on the input to each power converter for additional attenuation. The PPU input current sensor is also located in the input filter assembly. Two PWB assemblies contain the LPB input filter and the HPB filter capacitors.

The output module, shown in figure 10, contains high-voltage vacuum relays that switch the PPU outputs between two thrusters. It also contains a high current relay that switches the output of the discharge supply across the thruster grids to clear shorts caused by debris. Both of these functions are controlled by the DCIU simulator and can only be exercised while all outputs are disabled. In the grid clear function, the magnitude of the current can be selected to any value within the capability of the discharge supply and the pulse duration is operator controlled. One PWB assembly in the output module contains all the relay driver circuitry. 


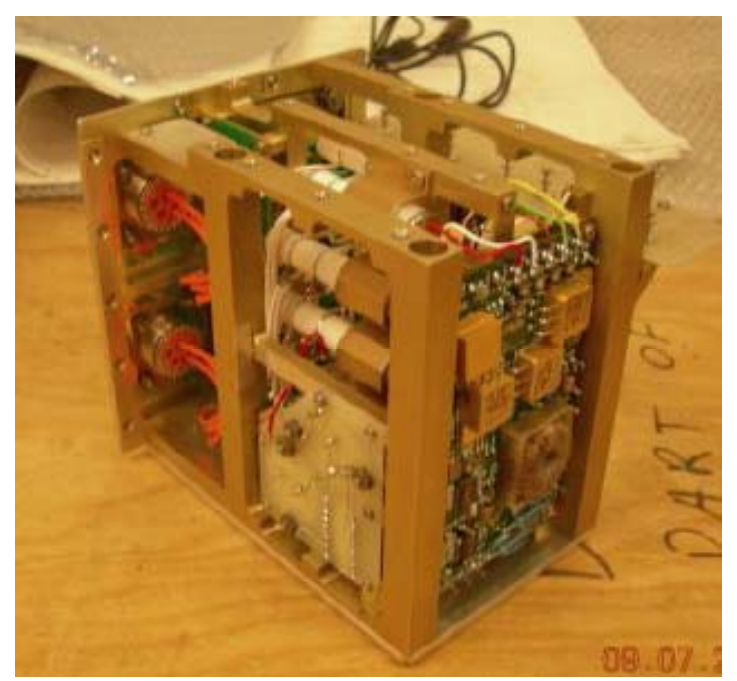

Figure 10.-Output module.

\section{Performance Test Results}

A bench top, resistive load performance test was conducted at L-3, in three phases, to verify the electrical performance and functionality of the PPU. The first phase tested each individual power supply through its entire operational range. In the second phase of testing, the PPU was operated at a variety of thruster operating conditions with increasing beam voltage and power and characterized operation of the recycle function by short-circuiting the outputs of the high voltage supplies. The last phase tested functions like grid clear, igniters, interlocks, and input protection.

\section{A. Module Performance}

All the modules that provide power to the thruster demonstrated full output range performance including margin. The neutralizer keeper supply met the 2.5 percent regulation requirement while all other supplies did better than 1.0 percent. The discharge supply output current ripple met the 5.0 percent requirement while all other supplies did better than 1.0 percent. The stand-by housekeeping power consumption is less than $13.4 \mathrm{~W}$. At $0.5 \mathrm{~kW}$ and 1 beam module it is $16.5 \mathrm{~W}$ and increases during operation with the number of operational beam modules up to a maximum of approximately $27.6 \mathrm{~W}$ with six beam modules.

\section{B. Efficiency}

Input and output conditions were measured while simulating thruster operating conditions to calculate efficiency of the EM PPU. It was attempted to match operating conditions as much as possible. However, a limited number of available resistive test load settings caused variations. Power efficiency was calculated as the ratio of the total output power and the HPB power. Losses associated with the housekeeping supply, slice, and internal controls are included in the total efficiency calculation. Total efficiency was calculated as the ratio of the total output power and the sum of the HPB and LPB power. Table 2 shows the results of this test done at a nominal input of $100 \mathrm{~V}$ and a baseplate temperature of approximately $30^{\circ} \mathrm{C}$. The EM PPU demonstrated a power efficiency of 94.5 percent and total efficiency of 94.1 percent at $6.8 \mathrm{~kW}$. Above $2.3 \mathrm{~kW}$, power and total efficiencies stayed above 93.0 and 92.2 percent, respectively. At $0.5 \mathrm{~kW}$, power efficiency was 85.1 percent while total efficiency was 82.6 percent. Efficiency drops at low power conditions because the housekeeping, discharge, neutralizer keeper, and accelerator supplies, each significantly less efficient than the beam supply, become a larger fraction of the total output power. Also, at low power, the beam supply operates at lower output voltage 
TABLE 2.-EM PPU EFFICIENCY AT SIMULATED THRUSTER CONDITIONS AND HIGH POWER BUS AT $100 \mathrm{~V}$

\begin{tabular}{|c|c|c|c|c|c|c|c|c|c|c|c|c|}
\hline \multirow{2}{*}{$\begin{array}{c}\text { Operational } \\
\text { Beam } \\
\text { Modules } \\
\end{array}$} & \multicolumn{2}{|c|}{ Beam } & \multicolumn{2}{|c|}{ Accelerator } & \multicolumn{2}{|c|}{ Discharge } & \multicolumn{2}{|c|}{ Neutralizer Keeper } & \multicolumn{2}{|c|}{ Power, W } & \multicolumn{2}{|c|}{ Efficiency, \% } \\
\hline & $\begin{array}{c}\text { Voltage, } \\
\text { V }\end{array}$ & $\begin{array}{c}\text { Current, } \\
\text { A }\end{array}$ & $\begin{array}{c}\text { Voltage, } \\
\text { V }\end{array}$ & $\begin{array}{c}\text { Current, } \\
\text { mA }\end{array}$ & $\begin{array}{c}\text { Voltage, } \\
\text { V }\end{array}$ & $\begin{array}{c}\text { Current, } \\
\text { A }\end{array}$ & $\begin{array}{c}\text { Voltage, } \\
\text { V }\end{array}$ & \begin{tabular}{|c|} 
Current, \\
A
\end{tabular} & Output & \begin{tabular}{|c|} 
House- \\
keeping
\end{tabular} & Power & Total \\
\hline 6 & 1800 & 3.480 & -249 & -40.4 & 25.17 & 19.62 & 10.94 & 3.15 & 6803 & 27.6 & 94.5 & 94.1 \\
\hline 6 & 1799 & 1.217 & -249 & -40.4 & 27.74 & 8.48 & 10.48 & 3.04 & 2466 & 27.2 & 94.3 & 93.3 \\
\hline 2 & 1799 & 1.219 & -249 & -40.4 & 27.68 & 8.48 & 10.51 & 3.05 & 2470 & 18.7 & 94.0 & 93.4 \\
\hline 6 & 1566 & 3.032 & -233 & -37.8 & 25.09 & 18.41 & 10.76 & 3.10 & 5251 & 27.4 & 94.2 & 93.8 \\
\hline 6 & 1397 & 2.713 & -219 & -35.5 & 24.30 & 16.62 & 10.62 & 3.06 & 4234 & 27.3 & 94.1 & 93.5 \\
\hline 4 & 1180 & 2.295 & -199 & -32.3 & 23.70 & 15.10 & 10.50 & 3.03 & 3104 & 23.5 & 93.6 & 92.9 \\
\hline 4 & 1021 & 1.893 & -175 & -28.4 & 24.30 & 13.63 & 10.44 & 3.02 & 2301 & 23.4 & 93.0 & 92.2 \\
\hline 1 & 650 & 1.210 & -144 & -23.3 & 25.95 & 9.59 & 10.48 & 3.04 & 1071 & 16.6 & 89.7 & 88.4 \\
\hline 1 & 276 & 0.808 & -500 & -80.9 & 22.00 & 8.07 & 10.43 & 3.03 & 472 & 16.5 & 85.1 & 82.6 \\
\hline
\end{tabular}

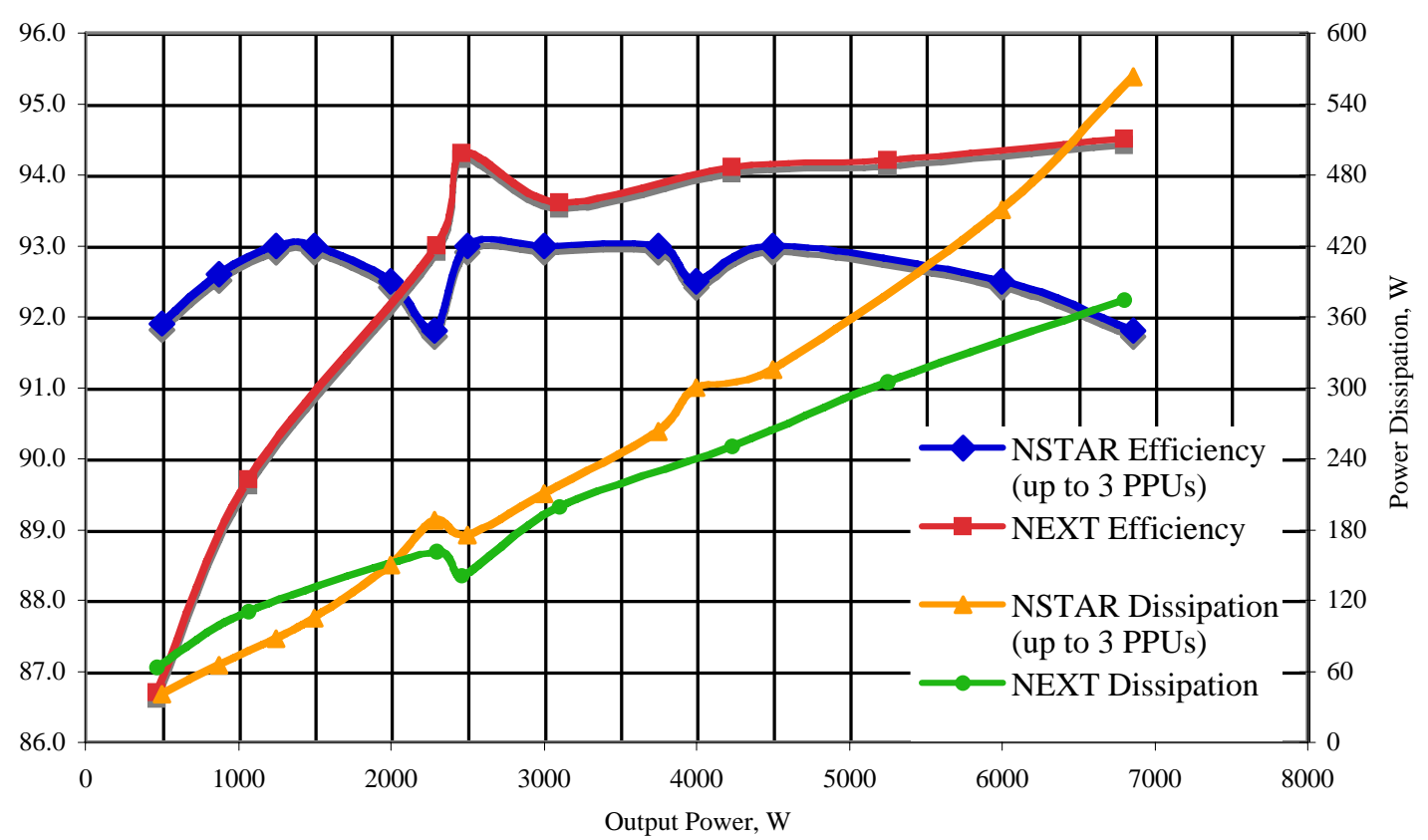

Figure 11.-Comparison of efficiency and power dissipation of NEXT versus NSTAR PPU at $100 \mathrm{~V}$ input.

and PWM mode, which is less efficient. The graph in figure 11 compares the power efficiency and power dissipation in a NEXT PPU against up to three NSTAR PPUs operating simultaneously to process an equivalent amount of power. At low power conditions, between 0.5 and $2.0 \mathrm{~kW}$, the NSTAR PPU is more efficient than the NEXT PPU. This is due to the NEXT PPU being in a 14:1 power throttle condition versus a 5:1 for the NSTAR PPU. However, this results in less than $20 \mathrm{~W}$ of additional power dissipation. Above $2.0 \mathrm{~kW}$, the NEXT PPU is more efficient than the NSTAR PPU and almost 3 percent at $6.9 \mathrm{~kW}$. This represents an additional $190 \mathrm{~W}$ of power dissipation that a spacecraft thermal rejection system would have to manage. This could result in a significant impact on spacecraft mass.

\section{Recycle Control and Fault Protection}

Figure 12 shows how the PPU outputs are sequenced during a recycle. When an over-current condition is detected, the high voltage supplies (beam and accelerator) are turned off and the discharge current is reduced to a "cutback" level. After approximately $400 \mathrm{~ms}$, the high-voltage is restored ensuring the accelerator supply leads the beam supply to avoid electron back-streaming. After the beam voltage is restored, the discharge current is released from the cutback level and slowly ramps-up to complete the sequence. The neutralizer keeper current remains constant during the entire event. Recycles were very repeatable regardless of operating conditions. The grid clear, interlocks, and input voltage protection functions performed according to the requirements. 


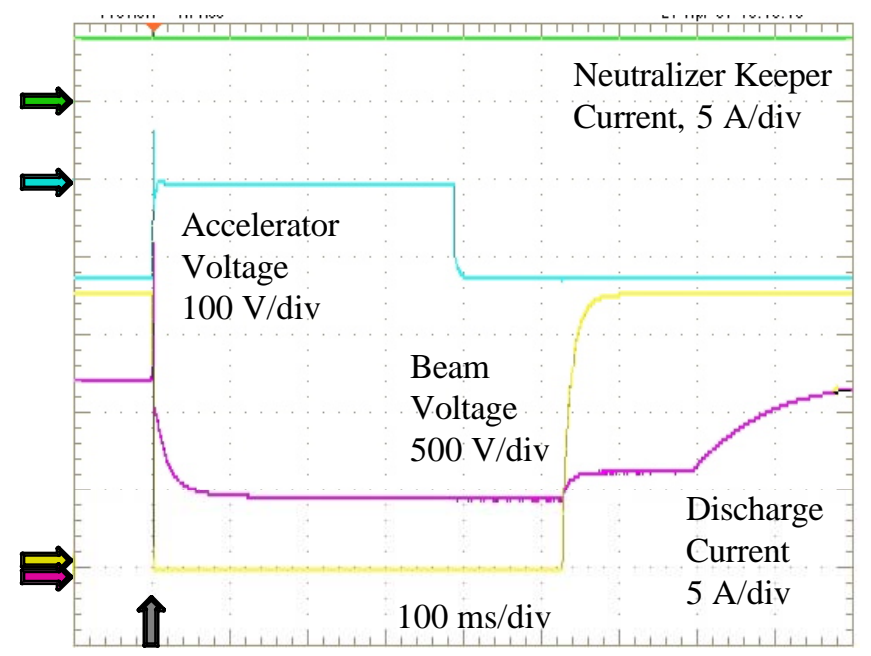

Figure 12.-Recycle sequence at full power.

\section{Output Control and Telemetry}

Telemetry and setpoint displays at the DCIU simulator were calibrated by individually running each power supply over its operational range. However, the accuracy was affected by apparent noise and offsets generated during simultaneous operation of the power supplies. The EM PPU will be re-calibrated using a modified procedure to compensate for these effects.

\section{E. Planned Testing}

After completion of the bench-top test, the PPU will be shipped to GRC for an integration test with an EM thruster. In this test, the PPU will be operated at a variety of conditions and power levels. Data of operating conditions, recycles, and output ripples will be collected to validate functionality of the PPU on a thruster load. After that the EM PPU will be sent to L-3 to undergo qualification level environmental tests including vibration, EMI/EMC, and thermal/vacuum.

\section{Summary}

Fabrication and bench-top testing of an EM PPU for the NEXT project was completed. This unit includes many innovative features to improve operational range, efficiency, flexibility, manufacturability, and cost over SOA PPUs. The EM PPU successfully demonstrated functionality during a bench-top performance test and closely met its performance goals. It is ready for a subsequent integration test with an EM thruster at GRC taking the NEXT ion propulsion system one step closer to maturity and becoming the choice for future NASA planetary missions.

\section{References}

1. Patterson, M. J. and Benson, S. W., "NEXT Ion Propulsion System Development Status and Performance,” AIAA-2007-5199, Joint Propulsion Conference, July 2007.

2. Patterson, M.J., Foster, J.E., Haag, T.W., Soulas, G.C., Pastel, M.R., and Roman, R.F., "NEXT: NASA’S Evolutionary Xenon Thruster Development Status,” AIAA-2003-4862, Joint Propulsion Conference, July 2003.

3. Soulas, G.C., Domonkos, M.T., and Patterson, M.J., "Performance Evaluation of the NEXT Ion Engine, AIAA-2003-5278, Joint Propulsion Conference, July 2003. 
4. Todd, P. C., Martinelli, R., Wiseman, S., Piñero, L. R., "Status of the NEXT 7 kW Power Processing Unit,” AIAA-2005-3868, Joint Propulsion Conference, July 2005.

5. Phelps, T. K., Wiseman, S., Komm, D. S., Bond, T., Piñero, L. R., "Development of the NEXT Power Processing Unit,” AIAA-2003-4867, Joint Propulsion Conference, July 2003.

6. Aadland, R.S., Frederick, H., Benson, S.W., and Malone, S., "Development Results of the NEXT Propellant Management System,” JANNAF Conference, 2005.

7. Monheiser, J., Aadland, R., and Wilson, F., "Development of a Ground Based Digital Control Interface Unit (DCIU) for the NEXT Propulsion System,” AIAA-2004-4112, Joint Propulsion Conference, July 2004.

8. Snyder, J.S., O’Connell, M.R., Fernandez, J.P., Wang, G., McNabb, R.S., and Crumb, D., “Vibration Test of a Breadboard Gimbal for the NEXT Ion Engine,” AIAA Paper No. 2006-4665, Joint Propulsion Conference, July 2006.

9. Patterson, M. J., Piñero, L., Aadland, R., and Komm, D., “NEXT Ion Propulsion System: SingleString Integration Test Results,” JANNAF Conference, May 2004.

10. Bond, T. A. and Christensen, J. A., "NSTAR Ion Thrusters and Power Processors,” NASA/CR-1999209162, November 1999.

11. Brophy, J., et al., "Development and Testing of the Dawn Ion Propulsion System,” AIAA-20064319, Joint Propulsion Conference, July 2006.

12. Brophy, J.R., “Preliminary Dawn IPS Lessons Learned,” JPL, September 9, 2005 (unpublished).

13. Brophy, J., et al., "Dawn Ion Propulsion System Peer Review” JPL, September 4, 2004 (unpublished).

14. Piñero, L.R., Bond, T., Okada, D., Pyter, J., Wiseman, S., "Design of a Modular 5-kW Power Processing Unit for the Next-Generation 40-cm Ion Engine,” IEPC-01-329, International Electric Propulsion Conference, February 2002.

15. Hamley, J. A., Cardwell, G.I., McDowell, J., Bond, T., Matranga, M., “The Design and Performance Characteristics of the NSTAR PPU and DCIU,” AIAA-98-3938, International Electric Propulsion Conference, July 1998. 


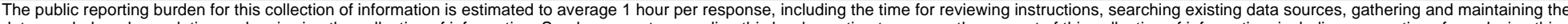

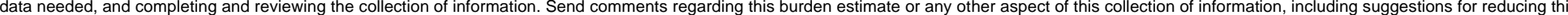

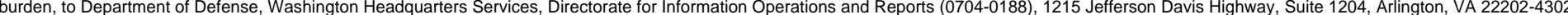

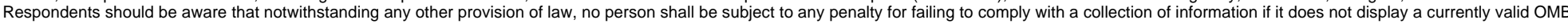
control number.

PLEASE DO NOT RETURN YOUR FORM TO THE ABOVE ADDRESS.

\section{REPORT DATE (DD-MM- $Y Y Y Y)$ \\ 2. REPORT TYPE \\ 3. DATES COVERED (From - To)}

01-12-2007

\section{TITLE AND SUBTITLE}

Technical Memorandum

Performance of the NEXT Engineering Model Power Processing Unit

5b. GRANT NUMBER

5c. PROGRAM ELEMENT NUMBER

\section{AUTHOR(S)}

Pinero, Luis, R.; Hopson, Mark; Todd, Philip, C.; Wong, Brian

\section{5d. PROJECT NUMBER}

5e. TASK NUMBER

5f. WORK UNIT NUMBER

WBS 346620.04.05.03.13

\section{PERFORMING ORGANIZATION}

REPORT NUMBER

E-16217

National Aeronautics and Space Administration

John H. Glenn Research Center at Lewis Field

Cleveland, Ohio 44135-3191

\section{SPONSORING/MONITORING AGENCY NAME(S) AND ADDRESS(ES)}

National Aeronautics and Space Administration

Washington, DC 20546-0001

\section{DISTRIBUTIONIAVAILABILITY STATEMENT}

Unclassified-Unlimited

Subject Category: 20

Available electronically at http://gltrs.grc.nasa.gov

This publication is available from the NASA Center for AeroSpace Information, 301-621-0390

\section{SUPPLEMENTARY NOTES}

\section{ABSTRACT}

The NASA's Evolutionary Xenon Thruster (NEXT) project is developing an advanced ion propulsion system for future NASA missions for solar system exploration. An engineering model (EM) power processing unit (PPU) for the NEXT project was designed and fabricated by L3 Communications under contract with NASA Glenn Research Center (GRC). This modular PPU is capable of processing up from 0.5 to 7.0 $\mathrm{kW}$ of output power for the NEXT ion thruster. Its design includes many significant improvements for better performance over the state-ofthe-art PPU. The most significant difference is the beam supply which is comprised of six modules and capable of very efficient operation through a wide voltage range because of innovative features like dual controls, module addressing, and a high current mode. The low voltage power supplies are based on elements of the previously validated NASA Solar Electric Propulsion Technology Application Readiness (NSTAR) PPU. The highly modular construction of the PPU resulted in improved manufacturability, simpler scalability, and lower cost. This paper describes the design of the EM PPU and the results of the bench-top performance tests.

\section{SUBJECT TERMS}

Electric propulsion; Ion propulsion; Electrostatic propulsion; Power processing unit

\begin{tabular}{|c|c|c|c|c|}
\hline \multicolumn{3}{|c|}{ 16. SECURITY CLASSIFICATION OF: } & \multirow{2}{*}{$\begin{array}{l}\text { 17. LIMITATION OF } \\
\text { ABSTRACT } \\
\text { UU }\end{array}$} & \multirow{2}{*}{$\begin{array}{l}\text { 18. NUMBER } \\
\text { OF } \\
\text { PAGES } \\
17\end{array}$} \\
\hline $\begin{array}{l}\text { a. REPORT } \\
\text { U }\end{array}$ & $\begin{array}{l}\text { b. ABSTRACT } \\
U\end{array}$ & $\begin{array}{l}\text { c. THIS } \\
\text { PAGE } \\
\text { U }\end{array}$ & & \\
\hline
\end{tabular}

10. SPONSORING/MONITORS
ACRONYM(S)
NASA
11. SPONSORING/MONITORING
REPORT NUMBER
NASA/TM-2007-215037; AIAA-2007-
5214

5214 

